\title{
"I Feel Like I Know Them": the Positive Effect of Celebrity Self-disclosure of Mental Illness
}

\author{
Amanda J. Calhoun ${ }^{1}$. Jessica A. Gold ${ }^{2}$ \\ Received: 29 November 2019 / Accepted: 4 February 2020 / Published online: 25 February 2020 \\ (C) Academic Psychiatry 2020
}

The media is often perceived as portraying psychiatric illness in a negative, stigmatizing, and even dangerous fashion [1]. In the case of suicide, it has long been documented that media reporting of celebrity suicides can lead to an augmentation in copycat suicides, a phenomenon historically known as the Werther effect [2]. After the highly publicized suicide of the actor Robin Williams, the average suicide rate increased from 113-117 to 142 suicide deaths per day. In addition, among the individuals who died by suicide immediately after the actor's death, around two-thirds of them used a method identical to that of Williams [3]. In contrast, calls for help also increase after celebrity deaths by suicide. The day after the death of Williams, calls placed to the National Suicide Prevention Lifeline (NSPL) increased by $300 \%$ [3], suggesting that media reporting of celebrity suicides may also promote help-seeking.

Collaborating with the media is particularly important given the changing landscape of information consumption. Currently, the general public is getting the bulk of their mental health education from movies, television, and entertainment news [4]. As such, representation of mental illness matters. Yet, mental illness is often left out of storytelling. For example, one study by the Annenberg Center found that out of 4598 film characters analyzed, only $1.7 \%$ experienced a mental health condition and out of 1220 TV characters, only $7 \%$ had psychiatric disorders. This is compared with the $18.9 \%$ of the population in the U.S. with mental illness [5]. Even if characters with psychiatric disorders are portrayed, the portrayals are often stigmatizing or incorrect; the mentally ill characters are often associated with words including "crazy," "weird," "psycho," and "freak" [5]. Besides possibly ostracizing those with mental illness in society, portraying psychiatric

Amanda J. Calhoun

Amanda.calhoun@yale.edu

1 Yale University, New Haven, CT, USA

2 Washington University, St. Louis, MO, USA illnesses incorrectly or not at all could have other consequences. Without knowing the facts about mental disorders, including the warning signs to recognize in themselves or others, help-seeking might be limited. As it stands, 35\% of American adults suffering from major depressive disorder did not receive treatment in 2017 [6]. Additionally, particular groups who are often underrepresented in both the media and mental health treatment [7] are at heightened risk for not identifying with mental illness portrayals. The Annenberg study found that of the characters with mental health conditions in the films sampled in the study, zero were LGB (lesbian, gay, bisexual) characters, none was transgender, only $7 \%$ were teens, and no characters in film were Hispanic/Latino or Native American [5]. Additionally, only 11 characters were Black or African American [5] even though it has been documented that they are more likely to experience severe psychiatric illnesses and are less likely to seek mental healthcare than their Caucasian counterparts [7].

This paper will attempt to counter the idea that media and celebrity culture are only a negative influence on mental health and, instead, will argue the potential benefits. It will discuss the positive portrayal of mental health in the media, specifically by celebrities, with the hypothesis that selfdisclosure and advocacy can lead to normalization and awareness of mental health in the general population and, hopefully, even encourage help-seeking.

\section{Celebrity Disclosure: Using Their Story}

Storytelling is a powerful tool found in many cultures around the world. As such, it has been used regularly in public health campaigns aimed at educating the masses about individuals with different diseases and making their experiences more tangible and relatable to the general population [8]. A recent study analyzing 157 celebrity health narratives found that they served three functions: education, inspiration, and activism [9]. In other words, celebrity disclosures of health issues 
helped to increase knowledge about the disease in the general public, inspire others with the same disease to seek help, and promote advocacy surrounding that particular illness [9]. This is true for mental health as well as other medical illnesses [9]. In fact, research has shown that if every member of the public knew someone with a mental illness, stigma would significantly decrease, highlighting the positive impact of selfdisclosure on normalization of mental health in the population [10].

The effect of self-disclosure on care-seeking may be one reason why the National Alliance on Mental Illness (NAMI) created the mental health storytelling initiative. This campaign aims to uses the power of celebrity narrative, such as that of NAMI spokesperson and current National Football League (NFL) player Chris Hubbard or actress Mayim Bialik, to destigmatize mental illness, to increase understanding of what it is like to live with a mental illness and promote empathy [11]. Fans might look to their favorite actress or athlete and think "if he/she/they got help, I could get help, too" or feel less alone because she/he/they had the same struggles.

However, self-disclosure does not always occur as a part of a coordinated advocacy campaign. In practice, many celebrities discuss their experiences in interviews, perhaps as a way to help fans or even to explain their own behaviors. Princess Diana was known for speaking openly and frankly about her battle with bulimia in a 1993 speech, which was received with wide admiration. Her honesty had lasting effects, as the number of women who sought treatment for bulimia doubled, a phenomenon called the "Diana effect" [12].

More recently, these conversations have only exponentially expanded. From athletes to models, to movie stars, and to Princess Diana's own sons, open discussions about mental health continue to increase awareness and expand the image of what it means to have a mental illness. Fans at home learn that it is not "taboo" to have a diagnosis or seek treatment for it, and talking about mental health becomes normalized. A study analyzing attitudes towards bipolar disorder after Demi Lovato's disclosure of her illness found that people who had a higher celebrity attachment to her had fewer negative stereotypes about those with bipolar disorder [10]. Her willingness to share with her fans through her music and social media, even more recently as she has struggled in her recovery after her apparent overdose, has had a positive impact on mental health, just like Princess Diana before her.

Other celebrities have chosen to write their stories. Carrie Fisher, best known for her role as Princess Leia on Star Wars, shared humorous and candid details about her bipolar disorder, from substance abuse to psychiatric hospitalization, to electroconvulsive treatment [13] in her books. In Wishful Drinking, she writes, "in my opinion, living with manic depression takes a tremendous amount of balls Not unlike a tour of Afghanistan (though the bombs and bullets, in this case, come from the inside)" [14]. Though her style was unique, many other celebrities started writing narratives and "coming out" stories thereafter including Brooke Shields' memoir on her postpartum depression, Down Came the Rain, and Gabourey Sidibe's memoir, This Is Just My Face: Try Not to Stare, on her suicidality and bulimia. Narrative self-disclosure has also grown to include blogs and social media posts, like Twitter and Instagram, especially as news platforms have shifted over time; about two-thirds of U.S. adults get their news from social media, with one in five using it frequently [15]. As one of the millions of followers of Ariana Grande, for example, one might learn of her struggles with post-traumatic stress disorder (PTSD), while a follower of Ryan Reynolds might hear about his with anxiety. No matter what media method is used for celebrity self-disclosure, given the high rates of media consumption [15], these stories have power and through social media, have only amplified their reach.

Self-disclosure of mental illness is, however, a complex personal decision with costs and benefits. As such, it is very important that no one, celebrities included, is forced into being a spokesperson for their disease if they are not fully ready and willing to do so. While self-disclosure can lead to discrimination and stigma aimed at the individual and this has happened in recent history, a query of self-disclosers showed that opening up about one's psychiatric illness can and has resulted in improved relationships, both personal and professional [16]. Self-disclosure of mental illness through narratives and storytelling is not a new concept, but it is an effective, positive, way for the media to engage around mental health.

\section{Celebrity Disclosure: Using Their Influence}

Some celebrities have gone a step beyond telling their stories and have been inspired to use their influence, through popularity and philanthropy, to start their own foundations and contribute to mental health treatment platforms. For example, though she has regularly talked about her own struggles with mental health in the media and in award shows, Lady Gaga founded the "Born This Way" Foundation [17] in 2011 to promote youth wellness and empowerment. It is launching a pilot program in Spring 2019 to train teens in Mental Health First Aid and, following recent mass shootings, is funding these projects in schools in affected school districts [17]. Another prominent example, "Bring Change 2 Mind" [18], was founded by Glenn Close in 2010 and was inspired by her sister's battle with bipolar disorder and her nephew's with Schizoaffective disorder [18]. Bring Change 2 Mind leverages the power of the media to promote mental illness awareness and advocacy through public service announcements, featuring celebrities sharing their stories, and by facilitating peer-topeer programs in high school and universities. The foundation has reached more than 2 billion people and helped more than 8000 students in the United States (U.S.) [18]. 


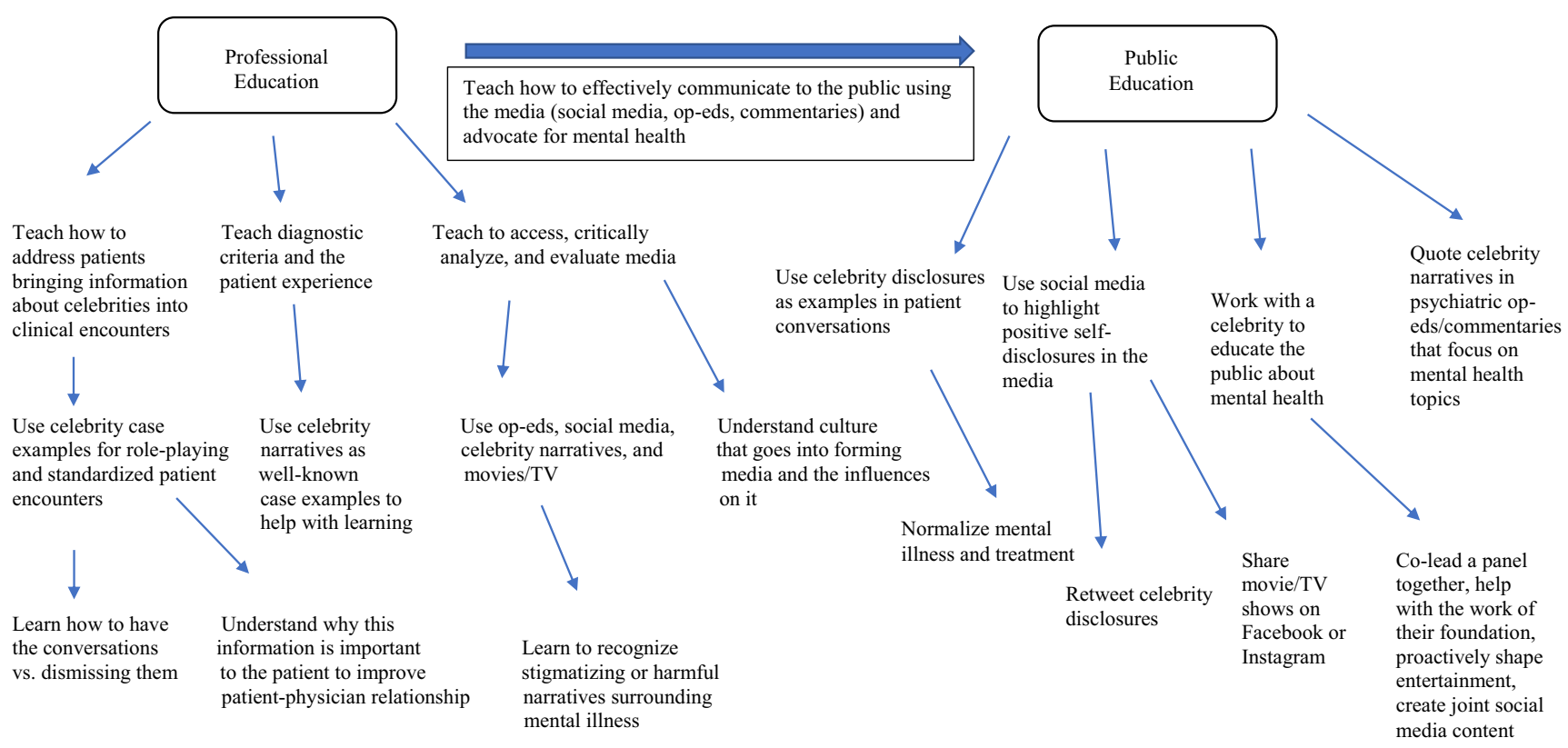

Fig. 1 Incorporating celebrity narratives into public and professional education

Beyond forming foundations to increase advocacy around mental illnesses, other celebrities have contributed to, advertised for, and even founded, mental health treatment centers or treatment methods. Perhaps the most famous example of this is Betty Ford, a former first lady who struggled with drug addiction and alcoholism and went on to found a treatment center that now bears her name, the Betty Ford Clinic. More recently, Michael Phelps became a spokesperson for Talkspace, an online psychotherapy platform. He has done commercials and interviews for them in which he discusses his own depression and suicidal ideation [19]. Though he is promoting a particular service, his honest discussion of his depression, his suicidal thoughts, and subsequent treatment will also normalize treatment and likely help many.

\section{Celebrity Disclosure: Using Their Identity}

As mentioned previously, portrayals of mental illness in the media are lacking, but in particular, they are lacking in underrepresented populations. Some celebrities, often by nature of who they are and what groups they represent, have helped advocate for populations that have historically struggled with help-seeking. One such group is men. In fact, a meta-analysis found that those who strongly adhered to masculine norms had poorer mental health outcomes and were less open to seeking mental health treatment [20]. There are few celebrities more adherent to this norm than former wrestler turned action star, Dwayne "The Rock" Johnson. Yet, he participated in an interview with Express, in which he opened up about his multiple bouts of depression, stating to readers: "You're not alone". In a later tweet about the interview (13.8 million followers as of September, 23, 2019), he related that depression can happen to anyone of any race, and that stigma exists surrounding mental health, especially for men [21]. This vulnerability was critical. In another recent example, Kevin Love, a basketball player for the Cleveland Cavaliers, disclosed his anxiety disorder and panic disorder in a piece for The Player's Tribune. His honesty has led to many conversations and the National Basketball Association (NBA) has even formed mental health initiatives and wellness programs as a result [22].

The African American population is another underrepresented group in mental healthcare. Some reasons for this include poorer quality of care due to racial biases in healthcare providers, distrust in the medical system, mental health stigma, and lack of racial/ ethnic diversity in mental healthcare providers [23]. Taraji P. Henson, an actress in the popular TV show "Empire" who suffers from depression, has been working to address mental health disparities in the African American community. In 2018, she founded her own organization, the Boris Lawrence Henson Foundation, named after her late father who had PTSD. It was inspired by the difficulty she encountered finding an African American therapist for her son after the murder of his father [24]. Her work aims to change the perception of and eliminate stigma surrounding mental illness in the African American community by increasing mental health resources in urban school settings, decreasing the rate of prison recidivism, and increasing the number of African American students deciding to pursue careers in therapy [24]. Jada Pinkett Smith is also a mental health advocate for this population. On her show Red Table Talk, which she co-hosts with her daughter, Willow Smith, and mother, Adrienne Banfield, she has shared her past depression and suicidality. Her show is now one of Facebook Watch's most successful shows with over 275 million views. Particularly for African American women, this show has become a movement, allowing them to openly and safely discuss difficult issues in 
Table 1 Benefits and pitfalls of using celebrity revelations in teaching

\begin{tabular}{|c|c|}
\hline Benefits & Pitfalls \\
\hline $\begin{array}{l}\text { May make diagnostic lecture topics more tangible and } \\
\text { interesting }\end{array}$ & $\begin{array}{l}\text { Could go against the Goldwater rule, which cautions } \\
\text { against psychiatrists making public statements } \\
\text { concerning diagnosis of public figures whom they } \\
\text { have not formally evaluated [26] }\end{array}$ \\
\hline $\begin{array}{l}\text { There is a truth in narrative that people relate to and } \\
\text { identify with as opposed to creating fictional cases }\end{array}$ & $\begin{array}{l}\text { If people cannot relate to the celebrities highlighted, or } \\
\text { do not recognize them readily, could cause a } \\
\text { disconnect }\end{array}$ \\
\hline $\begin{array}{l}\text { Patients and families will be more in touch (aware and } \\
\text { sometimes emotionally invested) with celebrity } \\
\text { narratives than academic patient vignettes and so, } \\
\text { students will know the stories too, which will help } \\
\text { them to stay "in touch" with their patients }\end{array}$ & $\begin{array}{l}\text { Could be seen as glorifying celebrities in a way that is } \\
\text { excessive or giving too much importance to status }\end{array}$ \\
\hline $\begin{array}{l}\text { Celebrities have greater reach in being able to } \\
\text { normalize and be inspiring for those with disorders } \\
\text { that might be considered stigmatizing, especially in } \\
\text { underrepresented groups }\end{array}$ & $\begin{array}{l}\text { "Trendy": Some cases might be dated and might only } \\
\text { be understood with substantial context. Have to stay } \\
\text { up with fast pace of cultural change }\end{array}$ \\
\hline $\begin{array}{l}\text { Can easily translate from professional education to } \\
\text { public education and not many topics can do that }\end{array}$ & $\begin{array}{l}\text { Celebrities might be being forced to disclose or } \\
\text { advocate without them fully wanting or being ready } \\
\text { to; The narratives might be inorganic, one-sided, } \\
\text { forced or curated through publicists }\end{array}$ \\
\hline
\end{tabular}

their community that affect mental health, including racism, transracial adoption, and domestic abuse [25]. Though these are just a few examples of unrepresented populations, by using their influence and intersectional identities, celebrities can lift up underserved groups and help make mental health identifiable, accessible, and relatable to all.

\section{Conclusion}

While there is no doubt that the media can portray mental health and psychiatric illnesses in a negative or inaccurate light, or not at all [5], and that it has known negative effects $[2,3]$, it can also serve as a powerful method of communication to increase awareness of mental health and normalize psychiatric illnesses. This effect is particularly important in underrepresented populations that have been previously left out of the mental health narrative and, as a result, have lower rates of care-seeking [7]. Psychiatrists must acknowledge that the media is not going away and the general population will continue to garner most of their mental health information from it [15]. Effective health communication and celebrity narratives can be incorporated into professional education for trainees and physicians, so that they can be used in future advocacy efforts and public education (Fig. 1).

Although the media has been damaging and stigmatizing and there are of course, pros and cons to enforcing messages using the media (Table 1 [26]), the information that it disseminates can also be informed by providers and shaped preventatively to produce positive, inclusive, and realistic images of mental illness. Psychiatrists could and should partner with the media and with celebrities to promote needed stories of mental health and selfdisclosure. By embracing the relationship, psychiatrists can make strides towards normalizing mental health diagnoses and treatment and emphasizing facts (like signs and symptoms) to patients. Psychiatrists might also be able to direct funding from celebrity foundations to evidence-based needs and use their influence to bring about real policy and change. If the aim of advocacy is to have large, powerful platforms to reach millions of potential patients, there is no better way than through celebrities and the media. It is time we stopped vilifying the media postmortem and instead, find a way to be on the same side.

\section{Compliance with Ethical Standards}

Conflict of Interest On behalf of both authors, the corresponding author states that there is no conflict of interest.

\section{References}

1. Stuart H. Media portrayal of mental illness and its treatments: what effect does it have on people with mental illness? CNS Drugs. 2006;20(2):99-106.

2. Phillips DP. The influence of suggestion on suicide: substantive and theoretical implications of the Werther effect. Am Sociol Rev. 1974;39(3):340-54.

3. National Institutes of Health. Crisis and suicide prevention services struggle with demand after celebrity suicides. U.S. Department of Health \& Human Services. 2019. https://www.nih.gov/news- 
events/news-releases/crisis-suicide-prevention-services-struggledemand-after-celebrity-suicides. Accessed 1 July 2019.

4. Fawcett K. How mental illness is portrayed in the misrepresented in the media: insidious portrayals on TV shape perceptions about reallife people with psychological disorders. US News \& World Report 2015. https:/health.usnews.com/health-news/health-wellness/ articles/2015/04/16/how-mental-illness-is-misrepresented-in-themedia. Accessed 1 May 2019.

5. Smith, SL, Choueiti M, Choi A, et al. Mental health conditions in film \& TV: portrayals that dehumanize and trivialize characters. USC Annenberg Inclusion Initiative, American Foundation for Suicide Prevention, and The David and Lura Lovell Foundation. 2019. http://assets.uscannenberg.org/docs/aii-study-mental-healthmedia_052019.pdf. Accessed August 20, 2019.

6. National Institute of Mental Health. Major Depression. https:// www.nimh.nih.gov/health/statistics/major-depression.shtml. Last updated $2019 \mathrm{Feb}$.

7. NAMI National Alliance on Mental Illness. African American Mental Health. African American Mental Health. 2019. https:// www.nami.org/find-support/diverse-communities/africanamericans. Accessed August 20, 2019.

8. Gray JB. The power of storytelling: using narrative in the healthcare context. J Commun Healthc. 2009;2(3):258-73.

9. Beck CS, Aubuchon SM, McKenna TP, Ruhl S, Simmons N. Blurring personal health and public priorities: an analysis of celebrity health narratives in the public sphere. Health Commun. 2013;29(3):244-56.

10. Wong NCH, Lookadoo KL, Nisbett GS. "I'm Demi and I have bipolar disorder" : effect of parasocial contact on reducing stigma toward people with bipolar disorder. Commun Stud. 2017;68(3).

11. Glaser E. Stopping stigmas with mental health storytelling. NAMI National Alliance on Mental Health Colorado Springs. 2017. https://namicoloradosprings.org/stopping-stigmas-mental-healthstorytelling/. Accessed 20 Aug 2019.

12. Hermann AM. The "Diana Effect" - how Princess Diana helped many seek help for bulimia. HD Today E-News: Insights from Human Development's Research \& Outreach. https://hdtoday. human.cornell.edu/2017/10/23/the-diana-effect-how-princessdiana-helped-many-seek-help-for-bulimia/. Accessed 1 May 2019.

13. Doyle S. Carrie Fisher's most feminist act was her frankness about being bipolar in a world where women are called "crazy". Quartz. 2016; https://qz.com/873813/carrie-fishers-bipolar-diagnosis-starwars-actress-was-the-ultimate-hero-for-people-with-mentalillness/. Accessed 1 May 2019.
14. Fisher C, Ravetch J. Wishful Drinking. New York: Simon \& Schuster; 2008.

15. Shearer E, Matsa KE. News use across social media platforms 2018. Pew Research Center. 2018. https://www.journalism/org/ 2018/09/10/news-use-across-social-media-platforms-2018/. Accessed on 1 Nov 2019.

16. Substance Abuse and Mental Health Services Administration. Selfdisclosure and its impact on individuals who receive mental health services. 2008. https://storage.googleapis.com/quantumunitsedcom/materials/2437_Self-Disclosure-and-Its-Impact-on-MentalHealth-Services.pdf. Accessed 1 July 2019.

17. Born This Way Foundation. https://bornthisway.foundation/aboutthe-foundation/. Accessed 1 Nov 2019.

18. Bring Change to Mind. https://bringchange2mind.org. Accessed 1 Nov 2019.

19. Holmes L. Michael Phelps opens up about how therapy improved his life. Huff Post. 2018. https://www.huffpost.com/. Accessed 1 Nov 2019.

20. Wong YJ, Ho MR, Wang SY, Miller IS. Meta-analyses of the relationship between conformity to masculine norms and mental health-related outcomes. J Couns Psychol. 2017;64(1):80-93.

21. McNamara B. Dwayne "The Rock" Johnson opened up about mental health. Teen Vogue. 2018. https://www.teenvogue.com/story/ dwayne-the-rock-johnson-opened-up-about-mental-health . Accessed 1 May 2019.

22. Aldridge D. NBA, NBPA taking steps to further address mental wellness issues for players. 2018. https:/www.nba.com/article/ 2018/03/12/morning-tip-nba-nbpa-addressing-mental-wellnessissues. Accessed 1 May 2019.

23. American Psychiatric Association. Mental health disparities: African Americans. 2017. Accessed 1 May 2019.

24. The Boris Lawrence Henson Foundation. 2018. https:// borislhensonfoundation.org/. Accessed 1 May 2019.

25. Ifeanyi FC. How Jada Pinkett Smith's "Red Table Talk" went from hobby to full-on movement. Fast Company. 2019. https://www. fastcompany.com/90298515/how-jada-pinkett-smiths-red-tabletalk-went-from-hobby-to-full-on-movement. Accessed 1 May 2019.

26. Kroll J, Pouncey C. The ethics of APA's Goldwater rule. J Am Acad Psychiatry Law. 2016;44(2):226-35.

Publisher's Note Springer Nature remains neutral with regard to jurisdictional claims in published maps and institutional affiliations. 